\title{
Association of Asthenopia and Convergence Insufficiency in Children with Refractive Error- A hospital based study
}

\author{
Gupta $R^{1}$, Sharma $B^{2}$, Anand $R^{3}$, Bawaria $S^{4}$, Dewada $R^{5}$ \\ ${ }^{1}$ Dr Rachna Gupta, Associate Professor, Regional Institute of Ophthalmology, Gandhi Medical College Bhopal, ${ }^{2}$ Dr Bhavna \\ Sharma, Assistant Professor, RIO, GMC, Bhopal, ${ }^{3}$ Dr Reena Anand, Director, RIO, GMC, Bhopal , ${ }^{4}$ Dr Shefali Bawaria, \\ Senior Resident, CIMS, Bilaspur, CG, ${ }^{5}$ Dr Rajesh Dewada, Resident, surgical officer, RIO, GMC, Bhopal, India
}

Address for correspondence: Dr Rachna Gupta, E mail: drrachnagupta2k@gmail.com

\begin{abstract}
Introduction: It is estimated that about $14 \%$ of people in India with visual impairment are suffering from refractive errors. The prevalence of childhood blindness in India is $0.17 \%$ and refractive errors alone are the major treatable cause (33.3\%) of the blindness. Assessment of Visual acuity should not be the only criteria for detection of ametropia, as children have strong accomodation. Thus it is emphasizing the importance of refraction testing under cycloplegic drugs. Convergence insufficiency is prevalent in about $7.5 \%$ of population. Purpose: To study the association of asthenopia and convergence insufficiency with refractive error in children. Methods: 2130 ametropic children up to 16 yrs were screened for asthenopia and convergence insufficiency. Result: Ametropia was found in 40.24\% of children .Myopia was prevalent in $47.41 \%$ children. Hypermetropia was detected in $15.49 \%$ children. Convergence insufficiency was observed in $34.14 \%$ of children and asthenopia was found in $82.19 \%$ ametropic children. Conclusion: The study reveals that, asthenopia and convergence insufficiency are found to be the most common ocular conditions associated with ametropia.
\end{abstract}

Key words: Convergence insufficiency, asthenopia, hypermetropia, Myopia, Refractive Error.

\section{Introduction}

Convergence insufficiency (CI) is a common binocular disorder and is associated with symptoms which become more prominent on doing near work ${ }^{1-3}$. Asthenopia is a very common presenting feature in children with refractive error and convergence insufficiency ${ }^{4,5}$. WHO reported that about 48 million people are blind in the world and 135 million are with low vision (3/60) and if any appropriate action in rehabilitating them has not taken, it is expected to be double by year $2020^{6}$. Vision 2020: The "Right to Sight" (a global initiation launched

Manuscript received: $13^{\text {th }}$ July 2013

Reviewed: 26 $^{\text {th }}$ Aug 2013

Author Corrected: $19^{\text {th }}$ Sep 2013

Accepted for Publication: 30 ${ }^{\text {th }}$ Oct 2013 by WHO and task force of International Non-Government Organizations) was launched in Geneva on Feb. 18, 1999 by the director general of the WHO, Dr. G.H. Brundtland with the aim to combat the gigantic problem of blindness and low vision in the world ${ }^{7}$. The incidence of CI in the general population is estimated to be 0.1 to $0.2 \%$. While exo deviations are present only in $1 \%$ of the general population, Asthenopia and CI are present in 11-19\% of children with an exodeviation ${ }^{9}$. There is great variability in the reported prevalence of CI ranging from 1.75 to $33 \%$, with the average prevalence reported to be approximately $5 \%$. Asthenopia is a group of symptoms experienced during near work, like headache, unable to 
see blackboard, eye ache, goes close to television, watering, blurring of vision during reading, picked up in school, frequent blinking/rubbing of eyes, redness of eyes, change in palpebral aperture, recurrent swelling of lids, double vision during reading/writing, burning sensation, deviation of eyes and frequent fall.

Asthenopic symptoms are more commonly experienced in children with uncorrected refractive error, general weakness, anemia, nutritional deficiency, extra ocular muscle weakness and latent strabismus ${ }^{10}$.

The prevalence of childhood blindness in India is $0.17 \%$ and it is estimated that about 14 percent of population would benefit from correction of refractive errors ${ }^{11}$.

Treatable refractive error is the major cause $(33.3 \%)$ of the blindness in children, ${ }^{6,11}$ (Global Initiative for the Elimination of Avoidable Blindness. Geneva: WHO. 1997). This study attempted to find the association of convergence insufficiency and asthenopia with refractive errors.

\section{Material and Methods}

Present study was undertaken at tertiary eye care centre of central India. Children up to 16 years were screened to find association of convergence insufficiency and asthenopia with refractive errors. It was a cross sectional hospital based study.

Inclusion criteria: children up to 16 years attending OPD.

Exclusion criteria: children $>16$ years, post traumatic and post surgical cases.

The demographic profile in terms of name, age, sex, address \& socioeconomic status were noted. Detailed history of patients was taken and symptoms were recorded in three categories
1) Ocular - pain in eyes, recurrent redness, deviation of eyes or heaviness.

2) Visual - Blurring of vision while reading or defective vision for distance or near.

3) Referred - headache, nausea or vomiting.

Family history of refractive error in siblings and parents, cerebral palsy or Down's syndrome or other relevant neurobehavioral abnormality was recorded. Personal history and any significant antenatal, perinatal and postnatal history were noted.

Visual acquity was noted and detailed ocular examination was conducted to look for any ocular morbidity.

Objective assessment of refractive error was done by Retinoscopy to evaluate the type and amount of ametropia and fundus examination was done under mydriasis to evaluate any posterior segment involvement ${ }^{12}$.

The cycloplegic used were atropine $1 \%$ eye ointment / homatropine $0.5 \%$ eye drop / cyclopentolate $1 \%$ / tropicamide $1 \%$ eye drops.

When the refraction had been measured objectively, fogging method of subjective estimation of refraction was done to induce a relaxation of accommodation in absence of cycloplegia ${ }^{12}$. Post mydriatic test was done and suitable spectacles were prescribed $^{12}$.

\section{Observation and Result}

Out of total 2130 ametropic children examined, myopia was found to be most commonly present (47.41\%) in children attending eye OPD, followed by myopic astigmatism (27.88\%).

Hypermetropia was present in $15.49 \%$ of children, followed by hypermetropic astigmatism (9.2\%). Comparing males and females, $(p=0.9)$ is statistically insignificant. 
Table No.1: Clinical profile of Convergence Insufficiency

\begin{tabular}{|l|l|l|l|}
\hline S.NO. & \multicolumn{1}{|c|}{ Complaints } & No. of cases & \% \\
\hline $\mathbf{1 .}$ & Headache & 1011 & 82.19 \\
\hline $\mathbf{2 .}$ & Unable to see blackboard & 923 & 75.04 \\
\hline $\mathbf{3 .}$ & Eye ache & 856 & 69.59 \\
\hline $\mathbf{4 .}$ & Goes close to television & 756 & 61.46 \\
\hline $\mathbf{5 .}$ & Watering & 603 & 49.02 \\
\hline $\mathbf{6 .}$ & Picked up in school & 213 & 17.31 \\
\hline $\mathbf{7 .}$ & Frequent blinking/frequent rubbing of eyes & 98 & 7.96 \\
\hline $\mathbf{8 .}$ & Redness of eyes & 98 & 7.96 \\
\hline $\mathbf{9 .}$ & Change in palpebral aperture & 84 & 6.8 \\
\hline $\mathbf{1 0}$ & Recurrent swelling of lids & 56 & 4.55 \\
\hline $\mathbf{1 1 .}$ & Deviation of eyes & 23 & 1.86 \\
\hline $\mathbf{1 2 .}$ & Frequent fall & 2 & 0.16 \\
\hline
\end{tabular}

It is observed that ametropic children present with varied clinical profiles. Headache being the most common presentation, accounts for $82.19 \%$, followed by unable to see blackboard in $75.04 \%$ and eye ache in $69.59 \%$. A significant no. of cases presented with goes close to TV $61.46 \%$, watering being next $49.02 \%$. Blurring of vision during reading was found in $31.03 \%$, and $17.31 \%$ cases were picked up during school screening programme.

Table No 2: Association of Hypermetropia and Myopia with Convergence Insufficiency and Asthenopia

\begin{tabular}{|l|l|l|l|l|l|l|}
\hline $\begin{array}{l}\text { Children with } \\
\text { refractive } \\
\text { error }\end{array}$ & $\begin{array}{l}\text { Hypermetropic } \\
\text { children }\end{array}$ & $\begin{array}{l}\text { Convergence } \\
\text { insufficiency and } \\
\text { asthenopia }\end{array}$ & $\begin{array}{l}\text { \% CI \& } \\
\text { Asthenopia }\end{array}$ & $\begin{array}{l}\text { Myopic } \\
\text { children }\end{array}$ & $\begin{array}{l}\text { Convergence } \\
\text { insufficiency } \\
\text { and asthenopia }\end{array}$ & $\begin{array}{l}\text { CI } \\
\text { Asthenopia }\end{array}$ \\
\hline GIRLS & 163 & 40 & 24.53 & 550 & 243 & 44.18 \\
\hline BOYS & 167 & 50 & 29.94 & 460 & 171 & 37.1 \\
\hline TOTAL & 330 & 90 & 27.27 & 1010 & 414 & 40.99 \\
\hline
\end{tabular}

Out of 330 hypermetropic children, convergence insufficiency was found in $27.27 \%$ of children and asthenopic symptoms were noted in $71.20 \%$. Males were relatively more affected $(29.94 \%)$ than females $(24.53 \%)$. Out of 1010 myopic children, convergence insufficiency was found in $40.99 \%$ and asthenopia was present in $81.02 \%$. Females $(44.18 \%)$ were relatively more affected than males $(37.10 \%)$.

Table No.3: Association of Convergence Insufficiency with degree of Hypermetropia and Myopia

\begin{tabular}{|l|l|l|l|l|l|l|l|}
\hline $\begin{array}{l}\text { Degree of } \\
\text { hypermetropia }\end{array}$ & $\begin{array}{l}\text { No. of } \\
\text { hypermetropic } \\
\text { children }\end{array}$ & $\begin{array}{l}\text { CI \& \& } \\
\text { Asthenopia }\end{array}$ & $\begin{array}{l}\text { \% CI \& } \\
\text { Asthenopia }\end{array}$ & $\begin{array}{l}\text { Degree of } \\
\text { myopia }\end{array}$ & $\begin{array}{l}\text { No. of } \\
\text { myopic } \\
\text { children }\end{array}$ & $\begin{array}{l}\text { CI \&sthenopia } \\
\text { Asta } \\
\text { CI \& } \\
\text { Asthenopia }\end{array}$ \\
\hline <+2 D & 96 & 70 & 72.91 & $<-2 D$ & 468 & 357 & 76.28 \\
\hline +2 D - +4D & 202 & 10 & 4.95 & -2 to -6D & 522 & 47 & 9.0 \\
\hline >+4D & 32 & 9 & 28.12 & $>-6 D$ & 20 & 13 & 65 \\
\hline
\end{tabular}

Out of 96 children with hypermetropia of $<+2$ D, 72.91\% had convergence insufficiency and asthenopia. Out of 468 children with myopia of $<-2$ D,76.28\% had convergence insufficiency and asthenopia followed by $65 \%$ children with myopia of $>-6 \mathrm{D}$. 
Table No 4: Association of Hypermetropic and Myopic Astigmatism with Convergence Insufficiency and Asthenopia

\begin{tabular}{|l|l|l|l|l|l|l|}
\hline & $\begin{array}{l}\text { Children with } \\
\text { Hypermetropic } \\
\text { astigmatism }\end{array}$ & CI and asthenopia & $\%$ & $\begin{array}{l}\text { Children with } \\
\text { Myopic } \\
\text { astigmatism }\end{array}$ & CI and asthenopia & $\%$ \\
\hline GIRLS & 104 & 10 & 9.61 & 346 & 77 & 22.25 \\
\hline BOYS & 92 & 12 & 13.04 & 248 & 74 & 29.83 \\
\hline TOTAL & 196 & 22 & 11.22 & 594 & 151 & 25.42 \\
\hline
\end{tabular}

$25.42 \%$ of children with myopic astigmatism had convergence insufficiency and asthenopia, where as $11.22 \%$ of children with hypermetropic astigmatism had convergence insufficiency and asthenopic symptoms.

Myopic astigmatism of $-2 \mathrm{D}$ to $-6 \mathrm{D}$ with the rule was observed in $2.35 \%$ males and $2.52 \%$ females, against the rule astigmatism in $1.95 \%$ males and $1.54 \%$ females, oblique astigmatism in $0.56 \%$ males and $0.65 \%$ females. Myopic astigmatism of $>-6 \mathrm{D}$ with the rule was observed in $0.08 \%$ males and $0.08 \%$ females, against the rule astigmatism in $0.16 \%$ males and $0.24 \%$ females, oblique astigmatism in $0.08 \%$ females. On comparing astigmatism in males and females, $\mathrm{p}$ value comes out to be 0.97 which is statistically insignificant. Of 2130 children with refractive error,69 were found to be anemic.

Table No 5: Association of Convergence Insufficiency and Asthenopia with Refractive Errors

\begin{tabular}{|l|l|l|l|}
\hline $\begin{array}{l}\% \text { of } \\
\text { children wypermetropic } \\
\text { asthenopia }\end{array}$ & $\begin{array}{l}\text { He of Myopic children } \\
\text { with and }\end{array}$ & $\begin{array}{l}\% \text { of children with } \\
\text { Hypermetropic astigmatism } \\
\text { with CI and asthenopia }\end{array}$ & $\begin{array}{l}\text { \% children with Myopic } \\
\text { astigmatism with CI and } \\
\text { asthenopia }\end{array}$ \\
\hline $27.27 \%$ & $40.99 \%$ & $11.22 \%$ & $25.42 \%$ \\
\hline
\end{tabular}

Highest association of convergence insufficiency and asthenopia was found with myopia (40.99\%), followed by hypermetropia (27.27\%). Least association was found with hypermetropic astigmatism $(11.22 \%)$.

Overall asthenopic symptoms were present in $81.02 \%$ myopic children with or without convergence insufficiency, as compared to $72.91 \%$ in hypermetropic children. Asthenopia and convergence insufficiency were found to be the most common ocular conditions with ametropia, $82.19 \% \& 34.14 \%$ respectively observed in cases presented in eye opd.

\section{Discussion}

The present study was carried out to study the association of asthenopia and convergence insufficiency with refractive error in children.

Out of total 2130 ametropic children, Myopia was found to be the most prevalent refractive error found in approximately $47.41 \%$ of children ${ }^{12}$. No significant difference in the incidence of refractive errors in boys and girls was noted ${ }^{13}$. Headache was the most common presentation $(82.19 \%)$ with convergence insufficiency and asthenopia, followed by unable to see blackboard and eye ache $^{14}$.

International Journal of Medical Research and Review
Convergence insufficiency and asthenopic symptoms were most common associated ocular conditions in

children with ametropia $^{15}$. Highest association of convergence insufficiency was found with myopia (40.99\%) followed by hypermetropia (27.27\%). Similar observations were made in the study done by D.J. Risovic et al. $2008^{16}$, which also showed that myopia as well as hypermetropia is significantly more frequent in the student group than in the nonstudent group.

The prevalence of refractive conditions in this study was found to be myopia $73.9 \%$, hypermetropia $1.5 \%$, and 
astigmatism $58.7 \%$. In today's scenario of reading and writing habits, specially keeping books close to eyes, are possible risk factors for myopia and development of asthenopic symptoms ${ }^{17}$.

Convergence insufficiency and symptoms of eye strain may prevent children from progressing with their peer group and may cause unnecessary social exclusion.

The study done by Chung and Chong ${ }^{18}$ supported the hypothesis that near esophoria is associated with high myopia. The study suggests that near phoria might be an important factor in myopia development. We did not consider myopia progression in our study.

\section{Conclusion}

Our study reveals that due to high prevalence of refractive errors among children, school vision screening is very important. Convergence insufficiency and asthenopia is

significantly associated with refractive errors ${ }^{3}$. For detection of ametropia, VA should not be the only criteria, as children have strong accommodation, also convergence insufficiency and latent hypermetropia both present with asthenopic symptoms, emphasizing the importance of refraction under cycloplegia.

Attention of parents and teachers regarding symptoms can be useful for early detection and treatment of asthenopia and convergence insufficiency.

The importance of diagnosing CI in children cannot be underestimated, because if left untreated can lead to difficulties in study which will increase each year with the increase of educational demands.

With early identification of asthenopic symptoms and detection of convergence insufficiency and health education, quality of vision can be maintained \& complications can be prevented.

Funding: Nil

Conflict of interest: Nil

Permission from IRB: Yes

\section{References}

1. Von Noorden GK. Binocular Vision \& Ocular Motility: Theory \& Management of Strabismus. $5^{\text {th }}$ ed. Mosby-Year Book; 1995:468-476.
2. Danchaivijitr C, Kennard C. Diplopia and eye movement disorders. J Neurol Neurosurg Psychiatry. Dec 2004;75 Suppl 4:iv24-31.

3. Rouse M W, Borsting E, Hyman L. Frequency of convergence insufficiency among $5^{\text {th }}$ and $6^{\text {th }}$ graders, Convergence insufficiency and reading study (CIRS) group. Optomvis sci. 1999: 76 (9): 643-9.

4. Mould WL: .Recognition of atypical convergence insufficiency: Pediatric ophthalmology 1970;7:212-4.

5. Sheedy, JE, Hayes JN, Engle. Is all asthenopia the same? Optomvissci 2003; 80 (ii): 732-9.

6. World Health Organization. Programme for the Prevention of Blindness And Deafness. Global Initiative for the Elimination of Avoidable Blindness. Geneva: WHO. 1997. p. 1-7

7. Wrigtht JD, Jr. Boger Wp, 3rd.visual complaints from healthy children. Surv. Ophthal. 1999.sept - oct; 44(2);113-21.

8. Arnoldi K, Reynolds J. A review of Convergence Insufficiency: What Are We Really Accomplishing with Exercises? AOJ 2007; 57: 123-130.

9. Govindan M, Mohney BG, Diehl NN, Burke JP. Incidence and Types of Childhood Exotropia. Ophthalmology. 2005 Jan;112(1):104-8.

10. Manson N. Anemia as aetiological factor in convergence insufficiency. May 1983, Volume 55, Issue 3, pp 177-198

11. Dandona $\mathrm{R}$ and Dandona $\mathrm{L} \quad \mathrm{Br} \quad \mathrm{J}$ Ophthalmol. Childhood blindness in India: a population based perspective 2003 March; 87(3): 263-265.

12. Duke-Elder's Practice of refraction / revised by David Abrams, (1978) vol 2, p.204.

13. Fotedar R, Rochtchina E, Morgan I, Wang JJ, Mitchell P, Rose KA. Principle of refraction in children2007 Aug;144(2):307-9.

14. Scheiman M, Herzberg H, Frantz K, Margolies M. A normative study of step vergence in elementary school children-J Am. Optom Assoc. 1989; 60 (4); 276-80.

15. Boston: Butterworths Classification of hyperopia (1987); Prevalence; Treatment; (1987):1010-19.

16. Quek TP, Chua CG, Chong CS, Chong JH, Hey HW, Lee J, Lim YF, Saw SM. Prevalence of refractive 
errors in teenage high school students in Singapore. Ophthalmic Physiol Opt 2004 Jan;24(1):47-55.

17.Wolfgang A Dusek, Barbara K Pierscionek and Julie F McClelland BMC Ophthalmology, An evaluation of clinical treatment of convergence insufficiency for children with reading difficulties 2011, 11:21,http:// www.biomedcentral.com/1471-2415/11/21

18. Chung KM, Chong E. Near esophoria is associated with high myopia. Clin Exp Ophthalmol 2000; 83: 71-5.

\section{How to cite this article?}

Gupta R, Sharma B, Anand R, Bawaria S, Dewada R. Association of Asthenopia and Convergence Insufficiency in Children with Refractive Error- A hospital based study. Int J Med Res Rev 2013;1(5): 222-227. doi: 10.17511/ijmrr.2013.i5.02. 